Creative processes in co-designing a codesign hub: towards system change in health and social services in collaboration with structurally vulnerable populations.

Micsinszki, Samantha, Buettgen, Alexis, Mulvale, Gillian, Moll, Sandra, Wyndham-West, Michelle, Bruce, Emma, Rogerson, Karlie, Murray-Leung, Louise, Fleisig, Robert, Park, Sean and Phoenix, Michelle

Suggested citation:

Micsinszki, Samantha, Buettgen, Alexis, Mulvale, Gillian, Moll, Sandra, Wyndham-West, Michelle, Bruce, Emma, Rogerson, Karlie, Murray-Leung, Louise, Fleisig, Robert, Park, Sean and Phoenix, Michelle (2021) Creative processes in co-designing a co-design hub: towards system change in health and social services in collaboration with structurally vulnerable populations. Evidence \& Policy, XX (XX). pp. 1-20. Available at http://openresearch.ocadu.ca/id/eprint/3576/

Open Research is a publicly accessible, curated repository for the preservation and dissemination of scholarly and creative output of the OCAD University community. Material in Open Research is open access and made available via the consent of the author and/or rights holder on a non-exclusive basis.

The OCAD University Library is committed to accessibility as outlined in the Ontario Human Rights Code and the Accessibility for Ontarians with Disabilities Act (AODA) and is working to improve accessibility of the Open Research Repository collection. If you require an accessible version of a repository item contact us at repository@ocadu.ca. 


\title{
research
}

\section{Creative processes in co-designing a co-design hub: towards system change in health and social services in collaboration with structurally vulnerable populations}

\author{
Samantha K. Micsinszki, micsinss@mcmaster.ca \\ Alexis Buettgen, buettgea@mcmaster.ca \\ Gillian Mulvale, mulvalg@mcmaster.ca \\ Sandra Moll, molls@mcmaster.ca \\ McMaster University, Canada \\ Michelle Wyndham-West, mwyndhamwest@faculty.ocadu.ca \\ OCAD University, Canada \\ Emma Bruce, gracee@mcmaster.ca \\ Karlie Rogerson, codesign@mcmaster.ca \\ Louise Murray-Leung, LMurray-Leung@lynwoodcharlton.ca \\ Robert Fleisig, robert@mcmaster.ca \\ Sean Park, parks5@mcmaster.ca \\ Michelle Phoenix, phoenimp@mcmaster.ca \\ McMaster University, Canada
}

\begin{abstract}
Background: Co-design is an approach to engaging stakeholders in health and social system change that is rapidly gaining traction, yet there are also questions about the extent to which there is meaningful engagement of structurally vulnerable communities and whether co-design leads to lasting system change. The McMaster University Co-Design Hub with Vulnerable Populations Hub ('the Hub') is a three-year interdisciplinary project with the goal of facilitating partnerships, advancing methods of co-design with vulnerable populations, and mobilising knowledge.
\end{abstract}

Aims and objectives: A developmental evaluation approach inspired by experience-based co-design was used to co-produce a theory of change to understand how the co-design process could be used to creatively co-design a co-design hub with structurally vulnerable populations.

Methods: Twelve community stakeholders with experience participating in a co-design project were invited to participate in two online visioning events to co-develop the goals, priorities, and objectives of the Hub. Qualitative data were analysed using a thematic content analysis approach. Findings: A theory of change framework was co-developed that outlines a future vision for the Hub and strategies to achieve this, and a visual graphic is presented.

Discussion and conclusions: Through critical reflection on the work of the Hub, we focus on the co-creative methods that were applied when co-designing the Hub's theory of change. Moreover, we illustrate how co-creative processes can be applied to embrace the complexity and vulnerability of all stakeholders and plan for system change with structurally vulnerable populations.

Key words co-design • structurally vulnerable populations • developmental evaluation • theory of change 


\section{Key messages}

1. Co-design processes are complex, requiring vulnerability, trust, flexibility, and a willingness to create and sustain change.

2. Innovative co-creation methods can elicit diverse experiences and impact change in services, systems, and policies.

To cite this article: Micsinszki, S. K., Buettgen, A., Mulvale, G., Moll, S., Wyndham-West, M., Bruce, E., Rogerson, K., Murray-Leung, L., Fleisig, R., Park, S. and Phoenix, M. (2021) Creative processes in co-designing a co-design hub: towards system change in health and social services in collaboration with structurally vulnerable populations, Evidence $\&$ Policy, vol XX, no XX, 1-20, DOI: 10.1332/174426421X16366319768599

\section{Introduction}

There is a growing international movement towards co-producing evidence and policy change in collaboration with health and social service users (rather than 'to', 'about', or 'for' them) and applying design thinking approaches as a new imperative for health and social system transformation (McDougall, 2012; Nicholas et al, 2019). Palmer et al (2019:247) refer to this movement as 'the new Zeitgeist - the spirit of our times', characterised by significant stakeholder involvement (for example, researchers, service users, people who deliver services, policymakers and so on) in health and social service quality improvement, service design/redesign, and evaluation. In this paper the term 'people with lived experience' (PWLE) refers to those who may experience structural vulnerability and those identified as family. Structural vulnerability is conceptualised as a product of social and systemic barriers (Moll et al, 2020) that may constrain access to health and social services (Grabovschi et al, 2013; de Freitas and Martin, 2015). By defining vulnerability in this way, we attempt to acknowledge and work to dismantle the structural mechanisms that exist (for example, racism, sexism, ableism and so on) which affect health and well-being (Katz et al, 2020). While our team, which includes PWLE, has reflected on the risks in labelling individuals as 'vulnerable' (Katz et al, 2020), we agreed to use the term structurally vulnerable to focus attention on policies, practices, and institutions that create power differentials, and to apply co-design to promote equity in the redesign of health and social services. Addressing the complex inequities faced by structurally vulnerable populations, such as those who experience systemic barriers to access health and social services (Bourgois et al, 2017), can be challenging and requires critical and innovative methodologies to mobilise for change (Sanders and Stappers, 2014; Mulvale et al, 2019; Moll et al, 2020).

Over the last decade, the term 'co-design' has emerged as a ubiquitous research and service/systems development approach across a range of disciplines (Slattery et al, 2020). Although many terms are used in the literature to describe similar concepts (McDougall, 2012), co-design broadly refers to utilisation of a personcentered research approach, and a design lens, to co-create solutions to problems or challenges (Moll et al 2020). Many discussions on the boundaries of co-design and what 'counts' as co-design exist in the literature but are beyond the scope of this paper (see Locock and Boaz, 2019; Metz et al, 2019; Nicholas et al, 2019). In this paper, the term co-design is used to describe the 'dynamic, creative approach to research that 
embraces partnership with community, and focuses on systems change and improving human experience' (Moll et al, 2020: 1). Cargo and Mercer (2008) outline three key values that define participatory research and partnerships involving PWLE: (1) trust and mutual respect; (2) capacity building, empowerment, and ownership; and (3) accountability and sustainability. However, it is not always clear how these approaches should be carried out in practice, particularly with structurally vulnerable populations (Mulvale et al, 2019; Moll et al, 2020).

Co-design with structurally vulnerable populations has the potential to contribute to broader system change toward more open and democratic health and social services (Hodges et al, 2006; Turner, 2014; Nicholas and Doberstein, 2016) but there is a lack of critical engagement with issues of power, institutional contexts and representation in co-production and co-design approaches (Farr, 2018; Mulvale et al, 2019; Palmer et al, 2019). For example, structural vulnerability in the healthcare context may arise from informational asymmetry between providers and patients (Bennett and Irwin, 1997), or from the overlapping and mutually reinforcing power hierarchies arising from socioeconomic barriers, racial discrimination, cultural considerations, and immigration status or labour force participation (Bourgois et al, 2017; Mulvale and Robert, 2021). Structurally vulnerable populations have historically been underrepresented in research engagement opportunities, limiting research relevance and transferability, and perpetuating exclusion from health services (Bonevski et al, 2014; Black et al, 2018; Gonzalez et al, 2020; Burgess and Choudary, 2021). Co-design research is thus seen as a way to affect the vulnerability of communities by acting upon systems, policies, individuals, groups, and institutions (Farr, 2018; Mulvale et al, 2021; Røhnebæk and Bjerck, 2021).

The need to develop a co-design hub was identified through past research with structurally vulnerable populations, including transitional-aged youth with psycho-social disabilities who faced personal and social challenges to accessing services. Similar challenges were heard at an international symposium involving 28 practitioners, academics, and service users involved in projects to co-design improved services for vulnerable populations in the public sectors of six countries (Australia, Canada, England, India, Scotland, and Sweden) (Mulvale et al, 2019). Development of a co-design hub at McMaster University was proposed to promote engagement, education, and innovation to advance co-design in health and social services and research to address the inequities faced by structurally vulnerable populations.

\section{A co-design with vulnerable populations hub}

The Co-Design Hub for the Health and Wellbeing of Vulnerable Populations (herein referred to as 'the Hub') is a three-year (2019-2022) initiative located at McMaster University in Hamilton, Ontario, Canada. The Hub brings together six interdisciplinary researchers whose primary disciplines include speech-language pathology, occupational therapy, engineering and biomedical engineering and design, design thinking/human-centred design, critical disability studies and programme evaluation, medical anthropology and health design, business and health research methodology; two students/trainees in rehabilitation sciences with backgrounds in nursing and occupational therapy; and two PWLE with interests and experiences in co-design and engagement related to service and system planning, community development and research at local, provincial and national levels. The Hub utilised 
a community engagement strategy to include community members in developing the Hub's vision, goals, outcomes, and plans for impact and sustainability through development of a theory of change.A theory of change is a comprehensive description of how and why an initiative is intended to create a desired change in a particular context (for example, Bickman, 1987; Patton, 2010; Mayne, 2015). This explication is often visually mapped out to make clear what a change initiative does (its strategies), and how these lead to desired goals being achieved. Theories of change can be used to promote mutual understanding and stakeholder agreement on the design of interventions and to identify and address equity and power issues (Mayne, 2015). In doing so, a theory of change can be an important tool to support the implementation process, adaptation of activities, and identify underlying assumptions and external factors that affect social change (Mayne, 2015).

In this paper, we describe our approach to co-designing the Hub's theory of change and focus specifically on the co-creative mechanisms that were used to engage with community members who have experiences in co-designing health and social services. The co-creation of the Hub's vision, strategies, and goals are part of a developmental evaluation that facilitates critical reflection, community collaboration, and iterative evolution over time. We present the co-creative methods that were applied when co-designing the Co-Design Hub (that is, the Hub's theory of change) to illustrate how co-creative processes can be applied to embrace vulnerability and engage diverse community members in inclusive and generative co-design initiatives.

\section{Methods}

A developmental evaluation (Patton, 2010) approach inspired by experience-based co-design (EBCD) (Bate and Robert, 2006), was used to to inform the development of the Hub and articulate the Hub's theory of change. Developmental evaluation is an iterative, non-traditional approach to evaluation and is particularly well suited to new projects where there is uncertainty about activities and outcomes (Dozois et al, 2010; Patton, 2010). Experience-based co-design (EBCD) is a step-by-step, creative, and iterative process chosen for its participatory and collaborative nature, user-centred design, as well as our team's previous experience in using this approach (Bate and Robert, 2006; Mulvale et al, 2019). EBCD begins with a focus on the experiences of PWLE and service providers, considering the 'touchpoints' or memorable moments that define their experiences (Point of Care Foundation, n.d.). The touchpoints are then explored in a systematic, collaborative process between researchers, PWLE, and service providers to prioritise areas for improvement, then co-create, and ideally implement solutions (Donetto et al, 2015). Outcomes of this process can include changes to structures, processes, relationships and/or technologies, and impacts that can range from improved service experiences to paradigm shifts in ideas and ways of doing business in systems and society (Plattner et al, 2012).

All members of the Hub team, including PWLE, were involved in the design and production of this work, including data analysis, writing, and co-authorship. An external evaluator $(\mathrm{AB})$ was hired to lead the developmental evaluation, which included collecting and analysing prospective and retrospective data (for example, observing team meetings, analysing feedback from educational events, interviews with team members and so on).The external evaluator was integral to the evaluation as they provided objectivity and credibility from their previous experience and knowledge of 
programme evaluation (Dozois et al, 2010). PWLE on the Hub team were involved throughout evaluation, including participating in team meetings, providing input and feedback, and participating in the cafés. Initial analysis identified the Hub team members' intent to engage more fully with the community who are involved in co-design in health and social services. Therefore, a community engagement strategy was utilised in which a purposeful sample of stakeholders, including PWLE with diverse experiences of structural vulnerability, were invited to participate in two virtual conversation cafés. Additional co-creative processes included a stakeholder team meeting and collaboration with a graphic design team to further develop and refine the theory of change. All study procedures were approved by the Hamilton Integrated Research Ethics Board at McMaster University (September 3, 2020).

\section{Participants}

Participants were identified through the networks of the Hub team members using a criterion-based purposeful sampling strategy. All participants had experience participating in or leading at least one completed co-design project with a focus with structurally vulnerable populations in the health or social service sector. A total of 12 participants took part in this process, two of whom were PWLE who were members of structurally vulnerable communities, and two were caregivers, with the intent of gathering an in-depth understanding of the meanings individuals attributed to their experiences with co-design (Hesse-Biber, 2007). For example, PWLE who participated had previous involvement with children and youth services, mental health services, family supports, and newcomer/settlement services. Participants representative of the following stakeholder groups were included: researchers, students, PWLE, and service providers, and several participants brought multiple perspectives on co-design. All participants were offered accessibility options, if needed, and PWLE were provided with an honorarium for their time.

\section{Data collection}

Two conversation cafés were hosted and videorecorded via Zoom. Café 1 was held in October 2020 with eight participants and focused on identifying touchpoints in their co-design experiences. Participants were asked to bring an object or visual image that represented their thoughts or experiences with the co-design process. This activity served as an introductory icebreaker and as a tool to explore what co-design meant to them. A semi-structured focus group guide was used to follow up on participants' memorable co-design moments, including positive and negative experiences, challenges, and tensions.

A follow-up café (café 2) was held in November 2020 with the original participants from café 1 and an additional four participants (two students, one researcher, and one service provider) who were unable to attend the initial café. Initial findings from café 1 were presented, then participants chose one of the three themes for more in-depth discussion in a break-out room. Consistent with a co-design process, each group brainstormed prototype solutions using Google Jamboard ${ }^{\mathrm{TM}}$, an interactive digital whiteboard that allows users to co-create in real time, to collectively illustrate how the Hub could address the identified themes (Point of Care Foundation, n.d.). A widely accessible digital medium that participants could access for no cost and from home 
was required due to the COVID-19 pandemic. Training was provided on how to use Google Jamboard ${ }^{\mathrm{TM}}$ at the beginning of the café session. A technology support person was available at each of the cafe sessions to support participants with Zoom or Jamboard ${ }^{\mathrm{TM}}$ access; options were provided to contribute verbally or via the Zoom chat function for anyone that preferred these mediums. Participants were asked prior to the cafés to notify the team if there were any accessibility needs we should consider and none were pre-identified. Each group, which included PWLE, was observed by a member of the Hub team and notes were taken about their co-design process. Participants had approximately 30 minutes to prototype during which time they completed individual brainstorming, then engaged in collective discussion to cluster similar ideas. Each group was asked to visually represent their prototype solution using the Google Jamboard ${ }^{\text {TM }}$ 'pen', 'sticky notes', or image functions. Each small group shared their prototype with the other groups, which facilitated larger group discussion about commonalities and next steps.

Once the cafés were completed, the Hub team invited key stakeholders (for example, one external partner with experience in community-based research and theory of change development, and one family member) to meet with the Hub team via Zoom to discuss findings from both cafés. The purpose of this meeting was to further articulate the goal of the Hub, the preconditions to achieve that goal, and the Hub's strategies. AB facilitated this process by providing guiding questions for the team to discuss, and Google Jamboard ${ }^{\mathrm{TM}}$ was used as a virtual whiteboard for collective thinking. Given the ongoing nature of this process, several iterations of the visual framework were developed and refined with the Hub team to conceptually and theoretically refine the theory of change.

A final creative process utilised by the Hub team involved working with a graphic design team, who were known to the Hub team, to create an image that represents the theory of change. Discussions occurred multiple times between January and June 2021 with both the full Hub team and a smaller working group, including feedback from PWLE, that collaborated with the graphic designer to simplify and refine the visual representation of the theory of change framework. These iterative design and feedback sessions were integral to facilitating the refinement of the imagery to be represented, the key concepts to portray, and the relationships between these concepts.

\section{Data analysis}

Observations of the process in each café and the audio-recordings were transcribed to electronic format and analysed using a thematic analysis approach (Braun and Clarke, 2006). Three team members (SM, AB, EB) independently reviewed the observation notes and transcripts, generated initial codes, and engaged in a group discussion to identify key touchpoints (themes) that captured elements of co-design raised during each café discussion. A written summary of the overarching touchpoints was created and shared with the Hub team for further discussion and refinement. Additionally, participants from café 1 were invited via email to provide feedback and reflections on the touchpoints related to opportunities and barriers prior to attending café 2 . Thematic content analysis was also used to analyse multiple data sources including observation notes taken by three team members during café 2, electronic transcripts from the audio-recording, and the Google Jamboards ${ }^{\mathrm{TM}}$ created by each group. 
Two team members analysed the data and a written summary was sent to the Hub team to review, prior to an initial theory of change development meeting.

\section{Development of theory of change}

Collectively, data from the conversation cafés, follow-up Hub team meetings, and sessions with the graphic design team, were used to inform development of a theory of change. To synthesise the data and develop the theory of change framework, a backcasting approach (Bibri, 2018) was used, which begins with the identification of a desired long-term goal and works backwards to identify all the pre-conditions (outcomes) that must be in place for the goal to occur, and how these causally relate to one another (Taplin et al, 2013).

\section{Findings}

\section{Co-design cafés}

Café 1 participants shared a variety of objects and images that represented their experiences with co-design. Objects and images included a neighbourhood map, a painter's palette, an image of a bridge, a train ticket and so on. These were described as metaphors for co-design experiences representing the human connection and the inherent messiness of the co-design process. For example, the bridge image was described as representing the connections built between various stakeholders that resulted in a sense of community. This initial activity naturally opened the conversation to allow the facilitator $(\mathrm{AB})$ to probe deeper about what was meant by these metaphors to understand the nature of participants' co-design experiences, their role on the project, motivation for getting involved and so on. Cafe 1 participants also shared suggestions on how co-design projects could be improved and how the Hub could address the challenges and tensions in co-design work. Three touchpoints in the co-design process were identified:

1. Authentic engagement. This was a recurring theme noted by many of the participants. They shared stories about situations when PWLE felt valued, respected, and empowered. Effective co-design was described as 'different people coming together' to mutually learn from each other's perspectives, but it was noted that it takes time to build trust and listen deeply and empathically. Participants explained that rushing to solutions sacrifices the process and co-design is 'all about the process'.

2. Inclusiveness. Another key issue raised by many participates relates to PWLE feeling excluded when co-design spaces and processes are inaccessible. They explained that 'accessibility' included clear and easy to understand language and terminology, physical accessibility, safe spaces for diverse people with various social identities, and meeting PWLE where they are located geographically and socially.

3. Institutional challenges with the co-design process. We heard many stories about institutional barriers to engaging participants from the earliest stages (for example, project conceptualisation and grant writing). Federal granting agencies and institutional research ethics boards could limit the time and flexibility needed to engage in co-design. 
Figure 1: Google Jamboard ${ }^{\mathrm{TM}}$ set up and instructions for café 2

\section{GROUP 1}

\begin{tabular}{l} 
THEME 1: AUTHENTIC ENGAGEMENT \\
Authentic engagement of service users/people with lived \\
experience makes them feel valued, respected, and empowered. \\
\hline ELEMENTS OF THIS THEME: \\
- Service users/people with lived experience should be \\
meaningfully involved in the design of health and social \\
services \\
- "People want to contribute but don't know how" \\
- Effective co-design involves "different people coming \\
together" to mutually learn from each other's perspectives \\
- It takes time to build trust, listen deeply and empathically. \\
Rushing to solutions sacrifices the process and co-design is \\
"all about process". \\
- Co-design goes beyond consultation and shifts power.
\end{tabular}

\section{DISCUSSION QUESTION: How might we advance co- design processes that foster authentic engagement} of people whose voices are not often heard?

\section{Use the "Expand Frame Bar" to} Navigate Between Frames

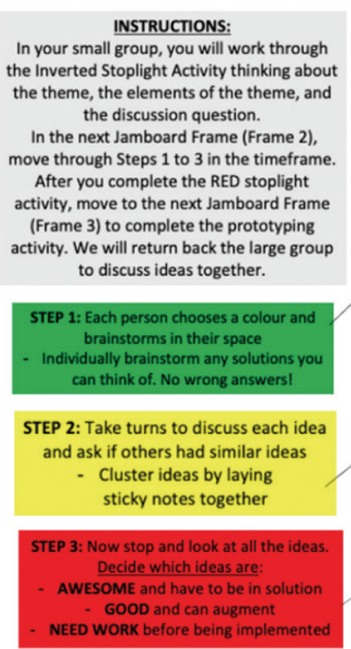

(Inverted) Stoplight Activity

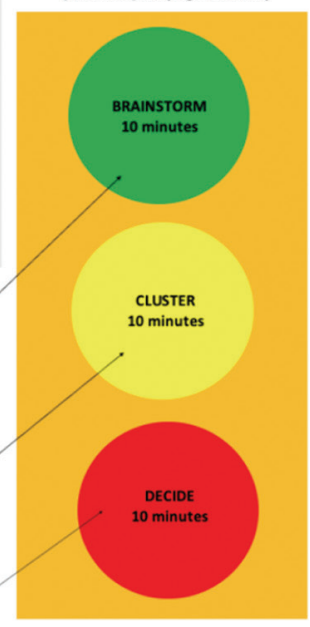

\section{STEP 1: Each person chooses a colour (10 mins) Individually brainstorm any solutions
you can think of. No wrong answers!}

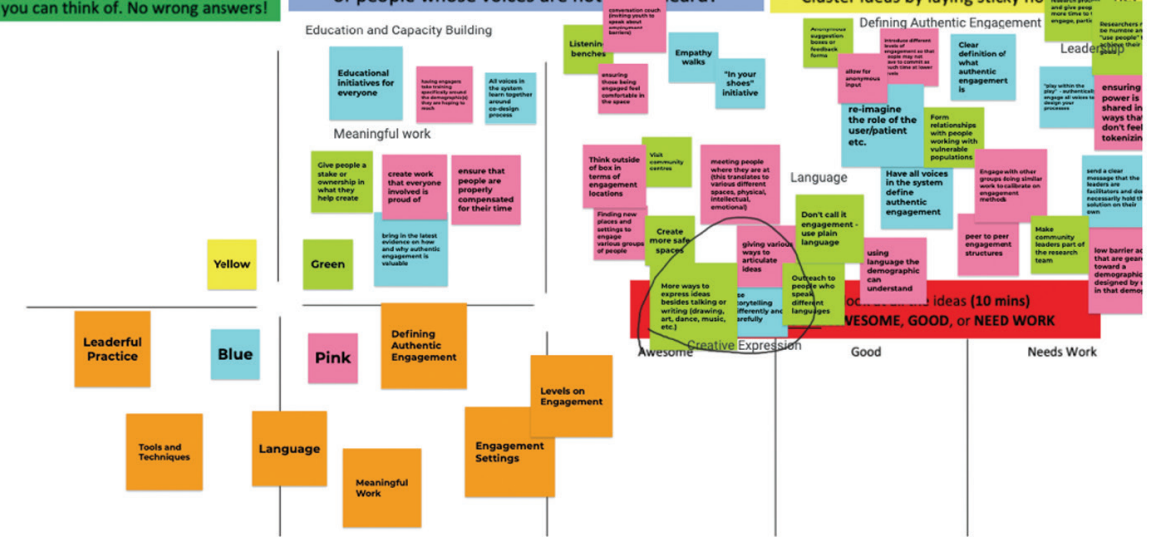

\section{DISCUSSION QUESTION: How might we advance cO- $\quad$ STEP 2: Take turns to discuss each idea and} sign processes that foster authentic engagement ask if others had similar ideas ( $\cdots n$ - m.n-1 Cluster ideas by laying sticky no

During café 2 , three visual prototypes were developed that suggested ways to address each of these touchpoints. Google Jamboards ${ }^{\mathrm{TM}}$ was used to facilitate this process in a way that encouraged democratic and accessible sharing between participants. Figure 1 shows how the Google Jamboard ${ }^{\mathrm{TM}}$ space was set up for group one, which was then tailored for each group and touchpoint issue. As shown in the figure, the first slide described main elements of the touchpoint, a guiding discussion question, and instructions on how to utilise the space. An inverted stoplight activity was used to illustrate the progression of the EBCD process from brainstorming and clustering possible solutions, and then deciding on a prototype. The second slide in the Google Jamboard ${ }^{\mathrm{TM}}$ illustrates the brainstorming and clustering process. Participants were asked to respond to the discussion question, for example, 'how might we advance co-design processes that foster authentic engagement of people whose voices are often not heard?'. To develop prototype solutions for the touchpoints, participants were asked to 'stick' as many ideas on the left side of the Google Jamboard ${ }^{\mathrm{TM}}$. Groups then clustered similar topics or concepts in the top right corner of the Google Jamboard ${ }^{\text {TM }}$ and then categorised them into 'awesome', 'good', and 'needs work' through group discussion. 
Figure 2: Google Jamboard ${ }^{\mathrm{TM}}$ prototype solutions to advance co-design processes that foster authentic engagement with structurally vulnerable populations

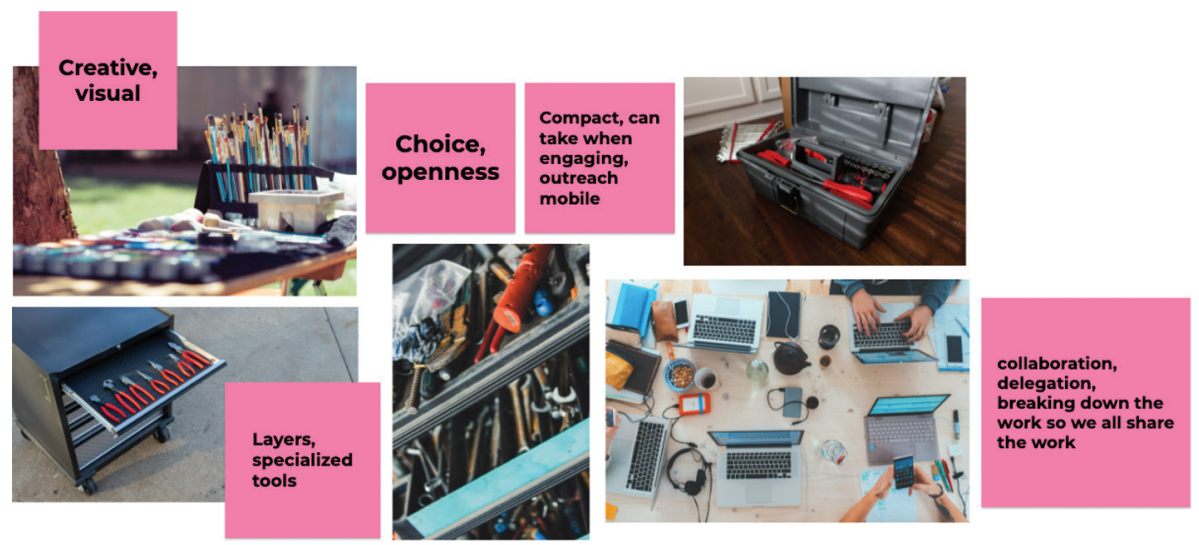

Note: images were modified slightly to include publicly available images for publication

Figure 2 illustrates the prototyping stage of this process for the first touchpoint: fostering authentic engagement with structurally vulnerable populations. As can be seen from the figure, participants illustrated that use of creative strategies, such as those that adopt visual activities and empower others through choice and flexibility, can help advance authentic engagement with structurally vulnerable populations. The process was represented as a compact set of tools that can be taken to where people are located, rather than requiring them to come to an institutional setting. Participants also emphasised the need for a collaborative and collective approach to sharing the workload and responsibility. Finally, there was recognition that contextually specific tools are needed to affect change at multiple levels, such as in interpersonal interactions, within teams, organisations, and at various public policy levels. For the Hub itself, participants recommended being a point of connectivity to highlight projects that embed fundamental co-design principles and facilitate cross-project learning and identification of needs.

Similar and different themes were heard in the other two breakout rooms. For example, we also heard from participants that there is a need to provide the necessary resources for accessibility of all stakeholders to participate in the co-design process (for example, time, bus/train tickets, financial compensation). This might also include using accessible software for meetings and considering virtual spaces to enhance diversity. To participants, inclusiveness also meant taking an empathic approach without judgement, whereby all participants are recognised as unique so that a 'one size fits all' approach is not appropriate. To address system-level changes that need to be addressed for meaningful co-design, participants explicitly discussed the need for continuous power sharing and equity. Infrastructures needed to support meaningful co-design research and practices included funding opportunities for PWLE; providing research ethics boards with the support to understand co-design (for example, training modules); and allowing ownership of knowledge produced by communities. It was important to participants that co-design projects provide opportunities for PWLE to lead so that decision making is not, as one participant wrote,'a one-time thing'. Taken together, analysis of the small group discussions in cafe 2 revealed several common recommendations and strategies for achievement, as shown in Table 1. 
Table 1: Recommendations for the Hub to advance co-design processes and strategies for achievement

\begin{tabular}{|c|c|}
\hline Recommendation for the Hub & Strategies for achievement \\
\hline $\begin{array}{l}\text { Promote vulnerability and the expression of } \\
\text { empathy among all stakeholders in the co-design } \\
\text { process. }\end{array}$ & $\begin{array}{l}\text { - Being vulnerable to shifts in power, decision } \\
\text { making, and uncomfortableness. } \\
\text { - Acknowledging and addressing privilege and } \\
\text { power. }\end{array}$ \\
\hline $\begin{array}{l}\text { Promote and support equitable, 'dynamic and } \\
\text { balanced' leadership in terms of 'community } \\
\text { leadership', and make community leaders part of } \\
\text { the research team. }\end{array}$ & $\begin{array}{l}\text { - Integrating shared leadership and power in } \\
\text { knowledge dissemination, and mobilisation. } \\
\text { - Fostering opportunities for community members } \\
\text { to lead the co-design process. }\end{array}$ \\
\hline $\begin{array}{l}\text { Provide tools, techniques, and resources from an } \\
\text { intersectional, equity focused perspective that } \\
\text { addresses the systemic barriers and challenges } \\
\text { for inclusive co-design in the health and social } \\
\text { service sector. }\end{array}$ & $\begin{array}{l}\text { - Develop templates for questions about } \\
\text { accessibility and inclusivity needs and preferences } \\
\text { of service users and diverse community members. } \\
\text { - Create tools for inclusive communication to } \\
\text { promote and support plain, culturally appropriate } \\
\text { language. } \\
\text { - Offer resources for digital equity to promote } \\
\text { inclusive access online (for example, French } \\
\text { interpretation, closed captioning, and so on). }\end{array}$ \\
\hline $\begin{array}{l}\text { Be a connector or facilitator of opportunities for } \\
\text { co-design work and education about co-design } \\
\text { including exemplars of good or positive } \\
\text { practices. }\end{array}$ & $\begin{array}{l}\text { Connect stakeholders with knowledge and } \\
\text { creative approaches for authentic engagement. }\end{array}$ \\
\hline
\end{tabular}

\section{Theory of change}

Drawing from the methods and themes described above, an initial visual for the theory of change was developed, as shown in Figure 3. This theory of change assumes a need for transformative change in the health and social service system. Specifically, there is a need for changes in the way services are designed, delivered, and evaluated to be inclusive of structurally vulnerable populations. As can be seen in Figure 3, the initial visual captures a logical, linear, and step by step visual of strategies and preconditions to achieve the goal of 'equitable partnership and meaningful engagement of marginalised service users in all aspects of identifying, planning, conceptualising, implementing and evaluating health and social services'. Co-design principles are used in creating, improving, and providing high-quality and equitable services. The identified preconditions for goal achievement included: a reallocation of decisionmaking power; embedding co-design values and principles in organisations and public policy; institutional recognition of co-design methods; and partnership with structurally vulnerable communities. This requires strategies from the Hub such as: knowledge sharing, collating best evidence and resources, engaging ethics boards and funding agencies, and engaging allies and people interested in doing co-design. Taken together, these strategies aim to facilitate dialogue and partnership formation to create safer, braver spaces for co-design and establish a network of people doing co-design work.

\section{Mechanisms}

The causal links in the theory of change pathway are supported by a set of assumptions that identify the mechanisms needed for each link in the causal pathway (Mayne, 2015). 
Figure 3: Co-Design VP Hub theory of change and outcomes framework, initial draft (January 20, 2021)

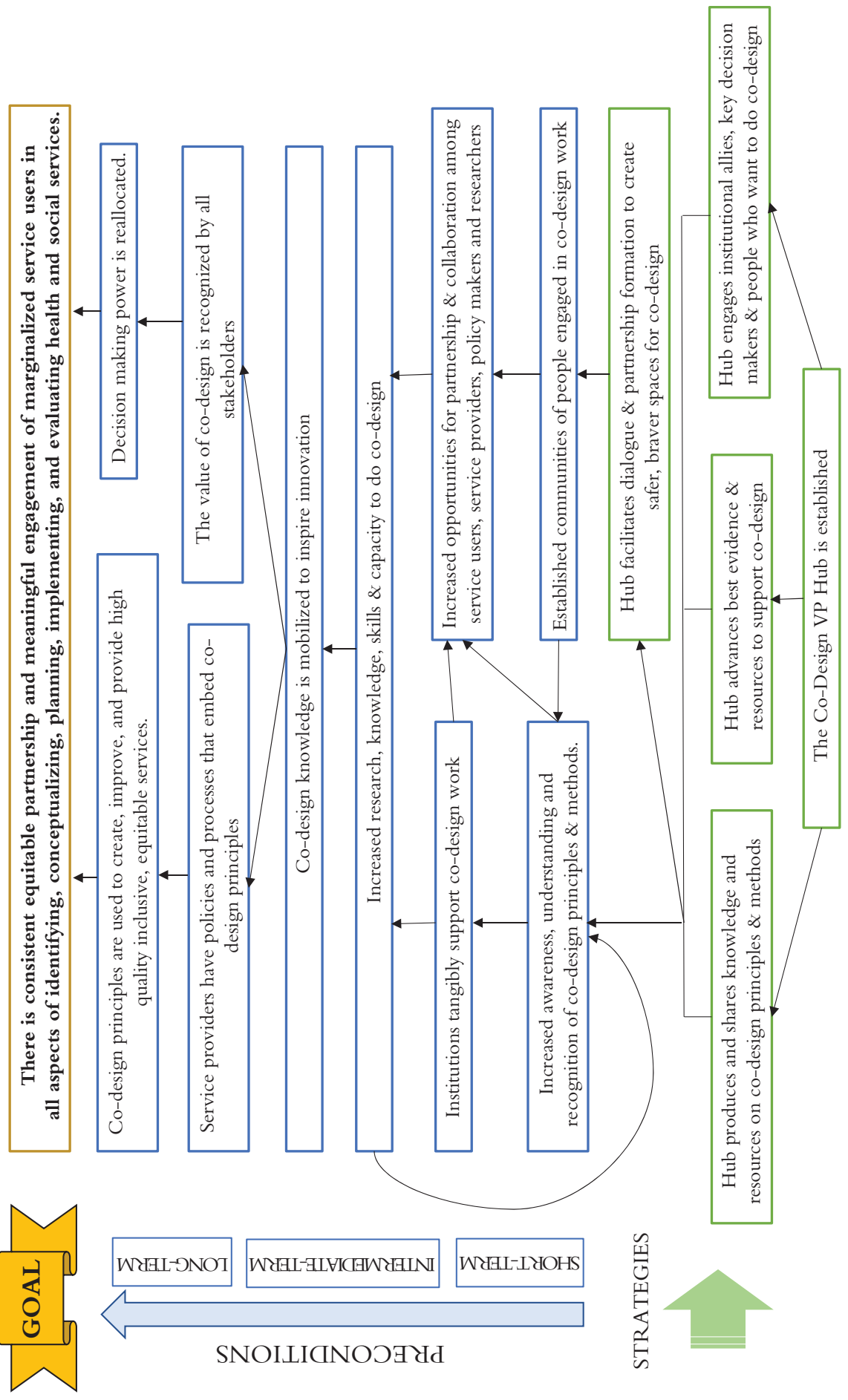


Mechanisms included: (1) reach (for example, identifying visible, hidden, and invisible forms of power); (2) capacity (for example, co-creating and sharing knowledge); and (3) behaviour change (for example, attending to structural components and dynamics that contribute to the vulnerability of PWLE (Westley et al, 2007; Palmer et al, 2019)). For the Hub, researchers, service providers, PWLE, and institutional allies (for example, funders) are essential stakeholders in the process of system change. The Hub needs to consider the way in which knowledge is shared to be accessible to various audiences. Service providers need to have the knowledge and capacity to change policies and processes to enact co-design and authentically engage PWLE in the design and implementation of health and social services.

\section{External influences}

Multiple external influences exist that have the potential to affect the realisation of the proposed outcomes and preconditions for the goal of the Hub (Mayne, 2015). This may include external initiatives with similar aims; economic and social trends; current systems being in inaccessible virtual and physical spaces; and influences of systemic racism, ableism, sexism, colonisation, and so on.

\section{Graphic design}

The theory of change content was accepted by our team and stakeholders, however feedback suggested that the linear presentation, which is typical of a theory of change diagram, failed to reflect two co-design processes by which the Hub can affect change.

We involved a graphic designer to enhance the visual by capturing additional:

1. Movement and fluidity. There are multi-level pathways with (a) micro (influencing people on the ground); (b) meso (organisation); and (c) macro (policy and systems) changes and change cycles between them. The Hub is connected at key moments to individual projects, organisations, and systems to create momentum to change (Wahl, 2019; see Park, 2021a).

2. People and relationships. The Hub is about people: power sharing, being vulnerable together and creating safer and braver spaces. Relationships, understanding others' perspectives, and generating empathy, are essential to the co-design process. Each stakeholder (for example, students, PWLE, families and other community members, community organisations, researchers) has a journey and a different experience and may need resources to get started. The work of the Hub is thus intersecting.

Inspiration for the theory of change graphic came in a variety of different mediums. Ideas for conceptualising these themes included a journey map depicting the co-design Hub journey at micro, meso, and macro levels (Han et al, 2018; see Park, 2021b); rainbow flow rings showing multiple perspectives and individual journeys laced into different rings where stakeholders 'meet' at different points within the ring (Mastermind Toys, 2021); an ecological metaphor of change with different seeds representing multiple perspectives, growing into a tree that produces different fruit; and the original conceptualisation for the Hub as a wheel with a hub and spoke model, 
Figure 4: Co-Design VP Hub theory of change draft visual with team feedback and suggestions (captured using the annotate feature in Zoom) (May 28, 2021)

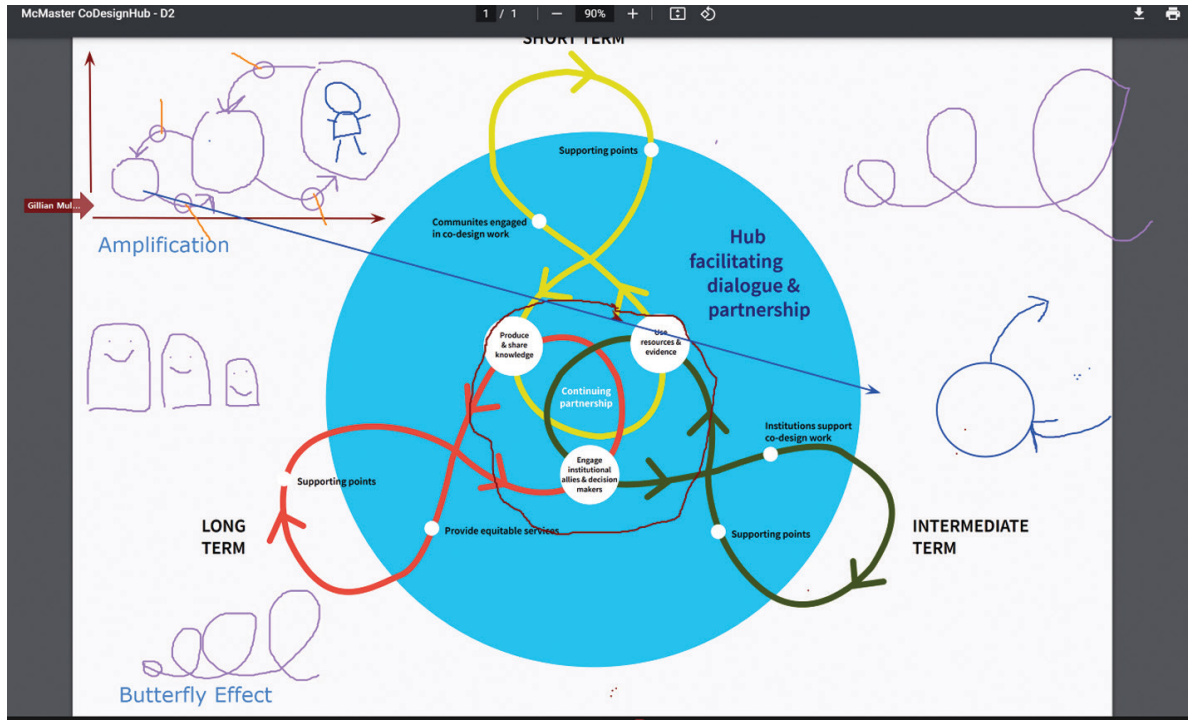

Figure 5: Co-Design VP Hub theory of change, final visual conceptualisation (June 25, 2021)

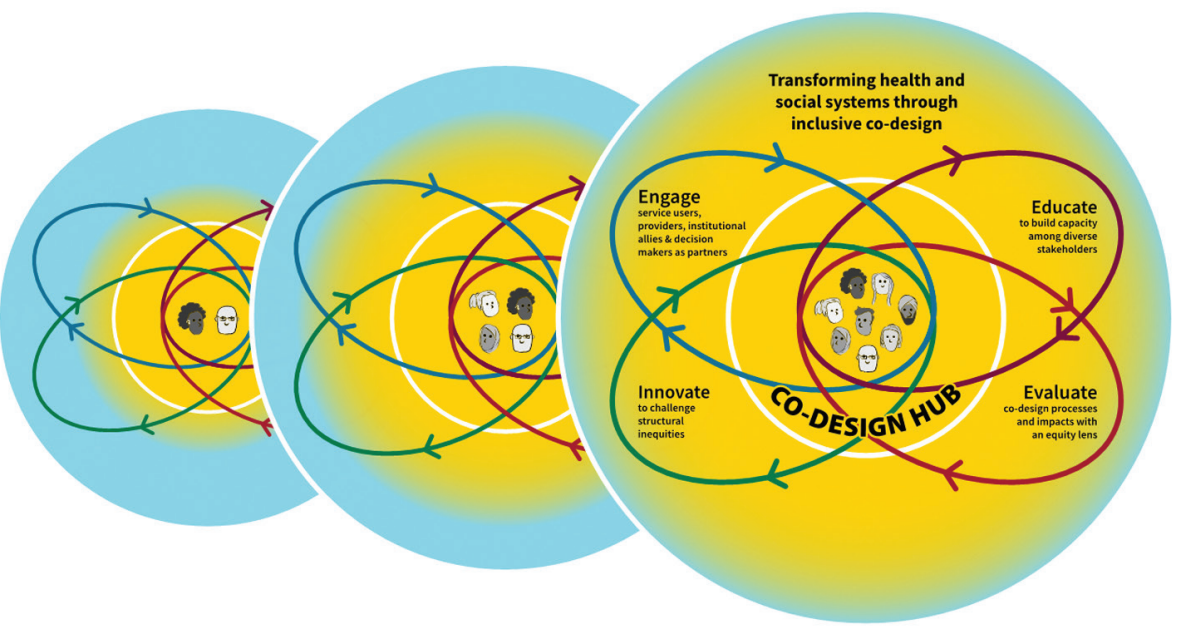

representing fluidity and movement. A draft of this process is shown in Figure 4. The final visual conceptualisation of the Hub's theory of change in Figure 5 shows the Hub and the communities engaged in this process as the heart of system transformation. The Hub's four overlapping foci (that is, education, evaluation, innovation, and engagement) are key drivers in the process of health and social service change. The progression of the circles shows amplification of the Hub's work over time, moving between micro, meso, and macro levels, and affecting greater impact with broaderreaching health and social service systems. 


\section{Discussion}

Previous issues of Evidence \& Policy raise the question of how creativity can be used as a mechanism in co-production and effect change in practice and policy, however the use of co-creative practices and descriptions of their effect in changing health and social services policy is still in its infancy (Metz et al, 2019). A developmental evaluation and EBCD process was used to develop a theory of change for a Hub designed to facilitate collaborative engagement with PWLE in improving health and social services. In doing so, we have described a range of challenges and opportunities involved in adopting co-design as a means to contest notions of vulnerability in health and social services. Challenges included authentic engagement, inclusiveness, and institutional barriers. To overcome some of these challenges, we employed a variety of co-creative practices as a way to make connections, build trust, and redistribute power (Spaniol, 2005).

We argue that innovative methods and co-creative strategies need to be used to create safe and brave spaces that are meaningful and authentic, and inclusive for co-design work to build capacity for change. Safe spaces are 'environments that promote honest interactions, cultural competence, training, and education', and are a central tenet of meaningful partnership (Canadian Institutes of Health Research, 2014: 11; Black et al, 2018; Hamilton et al, 2018). Moreover, inclusivity means that people from diverse backgrounds are included and have equal opportunities to engage through various practicalities (Liabo et al, 2020), including disability accommodations, inclusive communication (for example, text/chat box, verbal discussion with closed captioning, and so on), and promoting and supporting plain, culturally appropriate language.

The recommendation of enacting principles of inclusivity through entering invited spaces and supporting claimed and/or created spaces (Gaventa, 2006) is consistent with theories of social power, where invited spaces are those in which individuals are invited to participate by various kinds of authorities. In contrast, claimed and/ or created spaces can emerge naturally, typically by those who do not hold power (see also, Cornwall, 2004; Gaventa, 2006). For the Hub, this means that we need to develop creative outreach strategies to engage diverse groups in a way that explicitly recognises their position of power and influence in the change process. Participant suggestions for outreach and invitations to community members in spaces and places where they are gathered have led to development of a social network map to identify our connections and network gaps in reaching our target stakeholder groups. This approach to meeting participants where they are at is consistent with the principles of Mulvale et al's (2019) set of heuristics in which the co-design process is responsive, flexible, and enables participants to feel safe throughout the process. Moreover, recent frameworks can be used to navigate the multiple vulnerabilities within PWLE, service providers, researchers, and institutional infrastructure to establish a safe environment for collaboration (Mulvale et al, 2021) and to involve vulnerable participants in co-design and co-production (Amann and Sleigh, 2021) more generally.

We recognise however that the process of system change is complex (Cairney, 2020). According to Christens et al (2007: 231), attempts at systems change that account for movement toward greater complexity are 'typically flexible, with plenty of room for ambiguity. Competing perspectives can be held, and diversity is seen as an asset'. These are key characteristics of the co-design process. We frequently heard 
from participants about the importance of this process, but enacting authentic and meaningful co-design in research and practice can be challenging. Consistent with the literature, other touchpoints identified in our work included a lack of infrastructure to conduct meaningful co-design (Palmer et al, 2019); dominance of the medical model, exclusive procedures of healthcare organisations and professional regulators (Mulvale et al, 2019); and 'sociopolitical environments that privilege individualism over collectivism, self-sufficiency over collaboration, and scientific expertise over other ways of knowing based on lived experiences' (Moll et al, 2022). In moving towards system change, the Hub should work with allies and partners (for example, supportive service providers and institutional representatives) and promote and support equitable, dynamic, and balanced leadership. This requires shared leadership and power in co-design activities as well as in knowledge dissemination and mobilisation. Our findings suggest that the Hub needs to foster opportunities for community members to lead the co-design process, however, this cannot be done without sufficient resources including financial support (for example, compensation and accommodations) and institutional buy-in through value propositions to enable authentic engagement with community stakeholders. The Hub is working towards co-leadership with PWLE by developing a network and relationships with PWLE who lead co-design efforts in the community, conducting research to examine equity-based co-design projects that can advance best practices, and featuring the PWLE as leaders in co-design via our hosted presentations and conference planning. We continue to develop outreach strategies to engage more PWLE and service providers in the activities of the Hub, while also engaging institutional stakeholders to build awareness and knowledge of co-design to increase opportunities and break down barriers for inclusion beyond the Hub.

Throughout this project, we embraced the complexity of the process, which is particularly evident in the Google Jamboards ${ }^{\mathrm{TM}}$ (for example, Figure 1) created by café participants and our team. The modified EBCD process we used to co-create the Hub's theory of change allowed our team to engage with diverse stakeholder groups (for example, PWLE, service providers, policymakers, researchers) and intermediaries (for example, organisations, institutional partners) to brainstorm ideas and create prototypes. Google Jamboards ${ }^{\mathrm{TM}}$ created a space in which stakeholders could work together to develop prototypes in real time. EBCD is a flexible approach, and this feature allowed us to collaborate efficiently and effectively with diverse stakeholders who have different access to resources and funding and have different mandates and expectations (Dimopoulos-Bick et al, 2018).

Moving forward, the Hub intends to work in allyship and solidarity with the broader movement towards co-producing evidence and policy change in collaboration with PWLE. Our ongoing work will evolve in response to the needs and interests of various stakeholders, and the social, political, and economic contexts in which we are working. In co-designing transformative change in health and social services, we will continue to apply and promote creative methods to shift power and increase inclusion of structurally vulnerable populations.

\section{Strengths and limitations}

This work stems from a large interdisciplinary team that included two PWLE. Disability and other related accommodations were invited and provided as requested. Team members and research participants provided feedback in a range of formats 
including on documents, via email, and through discussion. Invitations to participate in this research were limited to individuals known to the Hub team and those with access to online engagement.Therefore, the co-design experiences of those who took part in this research may not be representative of other communities unknown to the Hub team. Moreover, not all participants took part in both cafés, and this might have affected responses of participants in café 2. For example, four participants who took part in café 2 were not part of sharing their co-design experiences in cafe 1 which were used by the team (with other resources) to identify touchpoints for the prototyping exercises in café 2. Lastly, due to the COVID-19 pandemic, the cafés and team meetings were conducted virtually. Although this enabled us to include applicants geographically outside of the Hamilton area, the online format may have limited the development of trust and connection, and participants expressed a desire to meet in person in the future.

\section{Conclusion}

This article presents our approach to co-designing a co-design hub through development of a theory of change. We illustrate the creative and collaborative ways in which co-design research can be undertaken to support the engagement of structurally vulnerable populations. Throughout this article, we have presented key visuals that illustrate co-creative practices which were used to elicit diverse experiences. Co-design processes are complex and require vulnerability among all stakeholders. We show how these processes can be used to authentically and meaningfully co-create a theory of change that will enable the Hub to support and impact change in services, systems, and policies.

\section{Funding}

The work of the Co-Design Hub with Vulnerable Populations is supported through the McMaster (SAF2019) Strategic Alignment Initiative.

\section{Acknowledgements}

The authors would like to thank everyone who took part in visioning and imagining the possibilities for the Co-Design Hub. The development of this manuscript was completed by the first author (SM) as part of a postdoctoral fellowship, supervised by the senior author (MP) at the School of Rehabilitation Science, McMaster University.

\section{Research ethics statement}

Approval was granted by the Research Ethics Board at McMaster University (HiREB \#10650; Sept 3, 2020).

\section{Author contribution statement}

The Co-Design Hub development and evaluation were conceptualised by all authors. The ideas in this manuscript were generated through team discussion and a first draft was prepared by SM, AB, and GM. All authors provided feedback on this manuscript by discussion or in writing and have approved the final submission.

\section{Conflict of interest}

The authors declare that there is no conflict of interest. 


\section{References}

Amann, J. and Sleigh, J. (2021) Too vulnerable to involve? Challenges of engaging vulnerable groups in the co-production of public services through research, International Journal of Public Administration, 44(9): 715-27, doi: 10.1080/01900692.2021.1912089.

Bate, P. and Robert, G. (2006) Experience-based design: from redesigning the system around the patient to co-designing services with the patient, Quality and Safety in Health Care, 15(5): 307-10, doi: 10.1136/qshc.2005.016527.

Bennett, K.C. and Irwin, H. (1997) Shifting the emphasis to 'patient as central': sea change or ripple on the pond?, Health Communication, 9(1): 83-93, doi: 10.1207/ s15327027hc0901_7.

Bibri, S.E. (2018) Backcasting in futures studies: a synthesized scholarly and planning approach to strategic smart sustainable city development, European Journal of Futures Research, 6(13): 1-27, doi: 10.1186/s40309-018-0142-z.

Bickman, L. (1987) The functions of program theory, New Directions for Program Evaluation, 1987(33): 5-18, doi: 10.1002/ev.1443.

Black, A., Strain, K., Wallsworth, C., Charlton, S.-G., Chang, W., McNamee, K. and Hamilton, C. (2018) What constitutes meaningful engagement for patients and families as partners on research teams?, Journal of Health Services Research and Policy, 23(3): 158-67, doi: 10.1177/1355819618762960.

Bonevski, B., Randell, M., Paul, C., Chapman, K., Twyman, L., Bryant, J., Brozek, I. and Hughes, C. (2014) Reaching the hard-to-reach: a systematic review of strategies for improving health and medical research with socially disadvantaged groups, BMC Medical Research Methodology, 14(42): 1-29, doi: 10.1186/1471-2288-14-42.

Bourgois, P., Holmes, S.M., Sue, K. and Quesada, J. (2017) Structural vulnerability: operationalizing the concept to address health disparities in clinical care, Academic Medicine, 92(3): 299-307, doi: 10.1097/ACM.0000000000001294.

Braun, V. and Clarke, V. (2006) Using thematic analysis in psychology, Qualitative Research in Psychology, 3(2): 77-101, doi: 10.1191/1478088706qp063oa.

Burgess, R.A. and Choudary, N. (2021) Time is on our side: operationalising 'phase zero' in coproduction of mental health services for marginalised and underserved populations in London', International Journal of Public Administration, 44(9): 753-66, doi: 10.1080/01900692.2021.1913748.

Cairney, P. (2020) The myth of 'evidence-based policymaking' in a decentred state, Public Policy and Administration, 0(0): 1-21, doi: 10.1177/0952076720905016.

Canadian Institutes of Health Research (2014) Strategy for patient-oriented research: patient engagement framework, https://cihr-irsc.gc.ca/e/documents/ spor_framework-en.pdf.

Cargo, M. and Mercer, S.L. (2008) The value and challenges of participatory research: strengthening its practice, Annual Review of Public Health, 29:325-50, doi: 10.1146/ annurev.publhealth.29.091307.083824.

Christens, B.D., Hanlin, C.E. and Speer, P.W. (2007) Getting the social organism thinking: strategy for systems change, American Journal of Community Psychology, 39(3-4): 229-38, doi: 10.1007/s10464-007-9119-y.

Cornwall, A. (2004) New democratic spaces? The politics and dynamics of institutionalised participation, Institute of Development Studies Bulletin, 35(2): 1-10, https://gsdrc.org/document-library/new-democratic-spaces-the-politics-anddynamics-of-institutionalised-participation/. 
de Freitas, C. and Martin, G. (2015) Inclusive public participation in health: policy, practice and theoretical contributions to promote the involvement of marginalised groups in healthcare, Social Science and Medicine, 135: 31-39, doi: 10.1016/j. socscimed.2015.04.019.

Dimopoulos-Bick, T., Dawda, P., Maher, L., Verma, R. and Palmer, V. (2018) Experience-based co-design: tackling common challenges, Journal of Health Design, 3(1): 86-93, doi: 10.21853/JHD.2018.46.

Donetto, S., Pierri, P., Tsianakas,V. and Robert, G. (2015) Experience-based co-design and healthcare improvement: realizing participatory design in the public sector, Design Journal, 18(2): 227-48, doi: 10.2752/175630615X14212498964312.

Dozois, E., Langlois, M. and Blanchet-Cohen, N. (2010) DE 201: A Practitioner's Guide to Developmental Evaluation, Montreal: J.W.McConnell Family Foundation and the International Institute for Child Rights and Development, https:// www.mcconnellfoundation.ca/assets/Media\%20Library/Publications/DE\%20 201\%20EN.pdf.

Farr, M. (2018) Power dynamics and collaborative mechanisms in co-production and co-design processes, Critical Social Policy, 38(4): 623-44, doi: 10.1177/ 0261018317747444.

Gaventa, J. (2006) Finding the spaces for change: a power analysis, Institute of Development Studies Bulletin, 37(6):23-33, https://www.powercube.net/wp-content/ uploads/2009/12/finding_spaces_for_change.pdf.doi:10.1111/j.1759-5436.2006. tb00320.x

Gonzalez, M., Phoenix, M., Saxena, S., Cardoso, R., Canac-Marquis, M., Hales, L., Putterman, C. and Shikako-Thomas, K. (2020) Strategies used to engage hard-toreach populations in childhood disability research: a scoping review, Disability and Rehabilitation, 43(19): 2815-27, doi: 10.1080/09638288.2020.1717649.

Grabovschi, C., Loignon, C. and Fortin, M. (2013) Mapping the concept of vulnerability related to health care disparities: a scoping review, BMC Health Services Research, 13(1): 94. doi: 10.1186/1472-6963-13-94

Hamilton, C.B., Hoens,A.M., Backman, C.L., McKinnon,A.M., McQuitty, S., English, K. and Li, L.C. (2018) An empirically based conceptual framework for fostering meaningful patient engagement in research, Health Expectations, 21(1): 396-406, doi: $10.1111 /$ hex.12635.

Han, N. et al. and for the DrugTEAM Study group (2018) Service design oriented multidisciplinary collaborative team care service model development for resolving drug related problems, PLoS ONE, 13(9): e0201705, doi: 10.1371/journal. pone.0201705.

Hesse-Biber, S.N. (2007) The practice of feminist in-depth interviewing, in S.N. Hesse-Biber, Feminist Research Practice, Thousand Oaks, CA: Sage.

Hodges, S., Ferreira, K., Israel, N. and Mazza, J. (2006) Strategies for system of care development: making change in complex systems, http://rtckids.fmhi.usf.edu/ rtcpubs/Study2_StrategiesSOCDev.pdf.

Katz,A.S., Hardy, B.J., Firestone, M., Lofters, A. and Morton-Ninomiya, M.E. (2020) Vagueness, power and public health: use of 'vulnerable' in public health literature, Critical Public Health, 30(5): 601-11, doi: 10.1080/09581596.2019.1656800.

Liabo, K., Boddy, K., Bortoli, S., Irvine, J., Boult, H., Fredlund, M., Joseph, N., Bjornstad, G. and Morris, C. (2020) Public involvement in health research: 
what does 'good' look like in practice?, Research Involvement and Engagement, 6(1): 1-11, doi: 10.1186/s40900-020-0183-x.

Locock, L. and Boaz, A. (2019) Drawing straight lines along blurred boundaries: qualitative research, patient and public involvement in medical research, co-production and co-design, Evidence \& Policy, 15(3): 409-21, doi: 10.1332/174 426419X15552999451313.

Mastermind Toys (2021) Rainbow flow rings, https://www.mastermindtoys.com/ products/rainbow-flow-rings.

Mayne,J. (2015) Useful theory of change models, Canadian Journal of Program Evaluation, 30(2): 119-42, doi: 10.3138/cjpe.230.

McDougall, S. (2012) Co-production, co-design, co-creation: what is the difference? Stakeholder design, https://www.stakeholderdesign.com/co-production-versusco-design-what-is-the-difference/.

Metz, A., Boaz, A. and Robert, G. (2019) Co-creative approaches to knowledge production: what next for bridging the research to practice gap?, Evidence \& Policy, 15(3): 331-37, doi: 10.1332/174426419X15623193264226.

Moll, S., Wyndham-West, M., Mulvale, G., Park, S., Buettgen,A., Phoenix, M., Fleisig, R. and Bruce, E. (2020) Are you really doing 'co-design'? Critical reflections when working with vulnerable populations, BMJ Open, 10(11): e038339, doi: 10.1136/ bmjopen-2020-038339.

Mulvale, G., Miatello, A., Green, J., Tran, M., Roussakis, C. and Mulvale, A. (2021) A COMPASS for navigating relationships in co-production processes involving vulnerable populations, International Journal of Public Administration, 44(9): 790-802, doi: 10.1080/01900692.2021.1903500.

Mulvale, G., Moll, S., Miatello, A., Robert, G., Larkin, M., Palmer, V.J., Powell, A., Gable, C. and Girling, M. (2019) Co-designing health and other public services with vulnerable and disadvantaged populations: insights from an international collaboration, Health Expectations, 22(3): 284-97, doi: 10.1111/hex.12864.

Mulvale, G. and Robert, G. (2021) Special issue: engaging vulnerable populations in the co-production of public services, International Journal of Public Administration, 44(9): 711-14, doi: 10.1080/01900692.2021.1921941.

Nicholas, G., Foote, J., Kainz, K., Midgley, G., Prager, K. and Zurbriggen, C. (2019) Towards a heart and soul for co-creative research practice: a systemic approach, Evidence \& Policy, 15(3): 353-70, doi: 10.1332/174426419X15578220630571.

Nicholas, N. and Doberstein, C. (2016) Exploring Effective Systems Responses to Homelessness, Toronto: The Canadian Observatory on Homelessness Press.

Palmer,V.J. et al. (2019) The participatory zeitgeist: an explanatory theoretical model of change in an era of coproduction and codesign in healthcare improvement, Medical Humanities, 45(3): 247-257, doi: 10.1136/medhum-2017-011398.

Park, S. (2021a) Hub cycles, https://www.dropbox.com/s/5nkg5ctddmljgtl/ hubcycles.pdf?dl=0.

Park, S. (2021b) Nested loop journey map, https://www.dropbox.com/s/ s51dpq2fknsjt1c/NestedLoopJourneyMap.pdf?dl=.

Patton, M.Q. (2010) Developmental Evaluation:Applying Complexity Concepts to Enhance Innovation and Use, New York: Guilford Press.

Plattner, H., Meinel, C. and Leifer, L.J. (2012) Design Thinking Research: Studying Co-creation in Practice, Understanding Innovation, New York: Springer. 
Point of Care Foundation. (n.d) EBCD:Experience-based co-design toolkit, https:// www.pointofcarefoundation.org.uk/resource/experience-based-co-design-ebcdtoolkit/.

Røhnebæk, M. and Bjerck, M. (2021) Enabling and constraining conditions for co-production with vulnerable users: a case study of refugee services, International Journal of Public Administration, 44(9): 741-52, doi: 10.1080/01900692.2021.1908355.

Sanders, E.B.N. and Stappers, P.J. (2014) Probes, toolkits and prototypes: three approaches to making in co-designing, CoDesign, 10(1): 5-14, doi: 10.1080/15710882.2014.888183.

Slattery, P., Saeri, A.K. and Bragge, P. (2020) Research co-design in health: a rapid overview of reviews, Health Research Policy and Systems, 18(1): 1-17, doi: 10.1186/ s12961-020-0528-9.

Spaniol, S. (2005) 'Learned hopefulness': an arts-based approach to participatory action research, Art Therapy, 22(2): 86-91, doi: 10.1080/07421656.2005.10129446.

Taplin, D.H., Clark, H., Collins, E. and Colby, D.C. (2013) Theory of change: technical papers, https://www.actknowledge.org/resources/documents/ToC-Tech-Papers. pdf.

Turner, A. (2014) Beyond housing first: essential elements of a system-planning approach to ending homelessness, School of Public Policy, 7(30): 1-25, https:// housingfirsttoolkit.ca/wp-content/uploads/beyond-housing-turner.pdf.

Wahl, D.C. (2019) Spatial and temporal scales in design thinking, https://blog. prototypr.io/spatial-and-temporal-scales-in-design-thinking-ba64336255b3.

Westley, F., Patton, M.Q. and Zimmerman, B. (2007) Getting to Maybe: How the World is Changed, Toronto:Vintage Canada. 